\title{
Sedentary Behaviors, Weight, and Health and Disease Risks
}

\author{
Hollie A. Raynor, ${ }^{1}$ Dale S. Bond, ${ }^{2}$ Patty S. Freedson, ${ }^{3}$ and Susan B. Sisson ${ }^{4}$ \\ ${ }^{1}$ Department of Nutrition, University of Tennessee, Knoxville, TN 37996, USA \\ ${ }^{2}$ Department of Psychiatry and Human Behavior, Brown Medical School, Providence, RI 02903, USA \\ ${ }^{3}$ Department of Kinesiology, University of Massachusetts, Amherst, MA 01003, USA \\ ${ }^{4}$ Department of Nutritional Sciences, University of Oklahoma Health Sciences Center, Oklahoma City, OK 73126, USA
}

Correspondence should be addressed to Hollie A. Raynor, hraynor@utk.edu

Received 1 November 2011; Accepted 1 November 2011

Copyright (C) 2012 Hollie A. Raynor et al. This is an open access article distributed under the Creative Commons Attribution License, which permits unrestricted use, distribution, and reproduction in any medium, provided the original work is properly cited.

Prior to the 1980s, very little thought was given to sedentary behaviors and how they may impact health. In 1985, the first study to investigate the relationship between a sedentary behavior, television viewing, and weight status was published by Dietz and Gortmaker [1]. In this study, the relationship between television viewing and weight status in children and adolescents was examined cross-sectionally and longitudinally, using data from the National Health Examination Survey. Results indicated that television viewing was positively related to the prevalence of obesity, both cross-sectionally and longitudinally. This investigation led to a growing body of research examining the mechanisms by which television watching impacted weight status and if reducing television watching could improve weight status in children. Outcomes from this area of research informed the development of the recommendation that screen time should be limited to $\leq 2$ hours per day in children [2].

Initially, the term "sedentary" was used to describe behaviors that were not considered to meet energy expenditure levels equivalent to moderate-intensity physical activity. Additionally, attention was focused on sedentary behaviors occurring during leisure time, thus television viewing and recreational computer use were the sedentary behaviors that were predominantly reported in early investigations of sedentary behaviors. Since the 1980s, sedentary behaviors have become more clearly defined and are now classified by energy expenditure level, similar to the way that physical activities are classified. Sedentary behaviors are characterized by minimal movement and a very low level of energy expenditure $(<1.5$ metabolic equivalent units (METs)) similar to that which is required to sit quietly $[3,4]$. Thus, sedentary pursuits are primarily sitting behaviors that occur in a variety of domains (i.e., leisure, occupation, transportation, and recreation) and include working/playing on the computer, driving a car, and watching television.

While sedentary behaviors have been associated with deleterious health outcomes in children for almost thirty years, sedentary behaviors are now also associated with morbidity in adults. Recent observational epidemiological research indicates that the more time spent being sedentary, independent of time engaging in physical activity, the greater the risk of developing type 2 diabetes [5], cardiovascular disease [5, 6], metabolic syndrome [7], weight gain [8-10], and obesity $[11,12]$. Furthermore, evidence suggests that sedentary behaviors are an independent risk factor for all-cause and cardiovascular-related mortality [5, 13-15].

There are many proposed mechanisms by which sedentary behaviors may negatively influence health. For television watching, it was initially proposed that watching television may reduce energy expenditure, by competing with time to engage in physical activity, and increase energy intake, by serving as a cue for eating [16-19]. However, there is growing evidence suggesting that engaging in increased amounts of sedentary behaviors can have adverse effects on health that are distinct from those related to insufficient physical activity $[4,14,20,21]$. Experimental studies show that prolonged sitting and lack of contraction of lower limb muscles lead to metabolic abnormalities via suppressed action of muscle lipoprotein lipase and insulin, supporting a unique "inactivity physiology" paradigm [20, 22-25]. Thus, sedentary behaviors may influence health via pathways that are independent of both physical activity and food consumption. Traditionally, while sedentary behaviors are believed to influence health through energy balance behaviors, the potential distinct 
mechanism by which sedentary behaviors may negatively influence health suggests that sedentary behaviors should potentially be targeted independently from physical activity and dietary intake in interventions designed to reduce risk type 2 diabetes, cardiovascular disease, and metabolic syndrome.

The purpose of this special issue is to explore some of the unresolved issues pertaining to sedentary behaviors, weight, and health and disease risk in children and adults. The papers in this special issue assist in broadening the understanding of the relationship between sedentary behaviors, weight, and health. The topics regarding sedentary behaviors addressed in this issue include assessment of sedentary behaviors, the relationship of sedentary behaviors with other health behaviors and outcomes, how energy expenditure during sedentary behaviors may be increased, and outcomes for interventions designed to reduce sedentary behaviors.

If experimental studies verify that sedentary behaviors are related to health outcomes that are public health priorities, continued research is needed to understand the pathways by which sedentary behaviors negatively impact health and how sedentary time can be reduced. Additionally, as the types and amount of sedentary behavior engaged in may be different in children versus adults due to differences in how time is spent and choices made about leisure-time activities, future research should investigate sedentary behaviors across the lifespan.

\section{Hollie A. Raynor Dale S. Bond \\ Patty S. Freedson Susan B. Sisson}

\section{References}

[1] W. H. Dietz and S. L. Gortmaker, "Do we fatten our children at the television set? Obesity and television viewing in children and adolescents," Pediatrics, vol. 75, no. 5, pp. 807-812, 1985.

[2] American Academy of Pediatrics, "Committee on Public Education: media education,” Pediatrics, vol. 104, pp. 341-343, 1999.

[3] R. R. Pate, J. R. O’Neill, and F. Lobelo, “The evolving definition of "sedentary"', Exercise and Sport Sciences Reviews, vol. 36, no. 4, pp. 173-178, 2008.

[4] N. Owen, G. N. Healy, C. E. Matthews, and D. W. Dunstan, "Too much sitting: the population health science of sedentary behavior," Exercise and Sport Sciences Reviews, vol. 38, no. 3, pp. 105-113, 2010.

[5] A. Grøntved and F. B. Hu, "Television viewing and risk of type 2 diabetes, cardiovascular disease, and all-cause mortality: a meta-analysis," Journal of the American Medical Association, vol. 305, no. 23, pp. 2448-2455, 2011.

[6] K. Wijndaele, S. Brage, H. Besson et al., "Television viewing and incident cardiovascular disease: prospective associations and mediation analysis in the EPIC norfolk study," PLoS One, vol. 6, no. 5, article e20058, 2011.

[7] A. Bankoski, T. B. Harris, J. J. McClain et al., "Sedentary activity associated with metabolic syndrome independent of physical activity," Diabetes Care, vol. 34, no. 2, pp. 497-503, 2011.

[8] R. A. Mekary, D. Feskanich, S. Malspeis, F. B. Hu, W. C. Willett, and A. E. Field, "Physical activity patterns and prevention of weight gain in premenopausal women," International Journal of Obesity, vol. 33, no. 9, pp. 1039-1047, 2009.

[9] K. Wijndaele, B. M. Lynch, N. Owen, D. W. Dunstan, S. Sharp, and J. F. Aitken, "Television viewing time and weight gain in colorectal cancer survivors: a prospective population-based study," Cancer Causes \& Control, vol. 20, no. 8, pp. 1355-1362, 2009.

[10] D. Mozaffarian, T. Hao, E. B. Rimm, W. C. Willett, and F. B. $\mathrm{Hu}$, "Changes in diet and lifestyle and long-term weight gain in women and men," New England Journal of Medicine, vol. 364, no. 25, pp. 2392-2404, 2011.

[11] F. B. Hu, T. Y. Li, G. A. Colditz, W. C. Willett, and J. E. Manson, "Television watching and other sedentary behaviors in relation to risk of obesity and type 2 diabetes mellitus in women," Journal of the American Medical Association, vol. 289, no. 14, pp. 1785-1791, 2003.

[12] J. E. Boone, P. Gordon-Larsen, L. S. Adair, and B. M. Popkin, "Screen time and physical activity during adolescence: longitudinal effects on obesity in young adulthood," International Journal of Behavioral Nutrition and Physical Activity, vol. 4, article no. 26, 2007.

[13] K. Wijndaele, S. Brage, H. Besson et al., "Television viewing time independently predicts all-cause and cardiovascular mortality: the EPIC Norfolk study," International Journal of Epidemiology, vol. 40, no. 1, pp. 150-159, 2011.

[14] A. A. Thorp, N. Owen, M. Neuhaus, and D. W. Dunstan, "Sedentary behaviors and subsequent health outcomes in adults: a systematic review of longitudinal studies, 19962011," American Journal of Preventive Medicine, vol. 41, no. 2, pp. 207-215, 2011.

[15] J. L. Veerman, G. N. Healy, L. J. Cobiac et al., "Television viewing time and reduced life expectancy: a life table analysis," British Journal of Sports Medicine. In press.

[16] L. H. Epstein, R. A. Paluch, A. Consalvi, K. Riordan, and T. Scholl, "Effects of manipulating sedentary behavior on physical activity and food intake," Journal of Pediatrics, vol. 140, no. 3, pp. 334-339, 2002.

[17] L. H. Epstein, J. N. Roemmich, R. A. Paluch, and H. A. Raynor, "Influence of changes in sedentary behavior on energy and macronutrient intake in youth," American Journal of Clinical Nutrition, vol. 81, no. 2, pp. 361-366, 2005.

[18] L. H. Epstein, J. N. Roemmich, R. A. Paluch, and H. A. Raynor, "Physical activity as a substitute for sedentary behavior in youth," Annals of Behavioral Medicine, vol. 29, no. 3, pp. 200209, 2005.

[19] D. M. Williams, H. A. Raynor, and J. T. Ciccolo, "A review of TV viewing and its association with health outcomes in adults," American Journal of Lifestyle Medicine, vol. 2, pp. 250259, 2008.

[20] M. T. Hamilton, D. G. Hamilton, and T. W. Zderic, "Role of low energy expenditure and sitting in obesity, metabolic syndrome, type 2 diabetes, and cardiovascular disease," Diabetes, vol. 56, no. 11, pp. 2655-2667, 2007.

[21] J. P. Thyfault and F. W. Booth, "Lack of regular physical exercise or too much inactivity," Current Opinion in Clinical Nutrition and Metabolic Care, vol. 14, no. 4, pp. 374-378, 2011.

[22] L. Bey and M. T. Hamilton, "Suppression of skeletal muscle lipoprotein lipase activity during physical inactivity: a molecular reason to maintain daily low-intensity activity," Journal of Physiology, vol. 551, no. 2, pp. 673-682, 2003.

[23] T. W. Zderic and M. T. Hamilton, "Physical inactivity amplifies the sensitivity of skeletal muscle to the lipid-induced downregulation of lipoprotein lipase activity," Journal of Applied Physiology, vol. 100, no. 1, pp. 249-257, 2006. 
[24] B. R. Stephens, K. Granados, T. W. Zderic, M. T. Hamilton, and B. Braun, "Effects of 1 day of inactivity on insulin action in healthy men and women: interaction with energy intake," Metabolism, vol. 60, no. 7, pp. 941-949, 2011.

[25] A. Bergouignan, F. Rudwill, C. Simon, and S. Blanc, "Physical inactivity as the culprit of metabolic inflexibility: evidence from bed-rest studies," Journal of Applied Physiology, vol. 111, no. 4, pp. 1201-1210, 2011. 


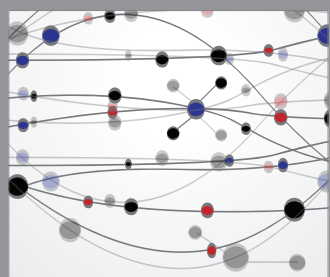

The Scientific World Journal
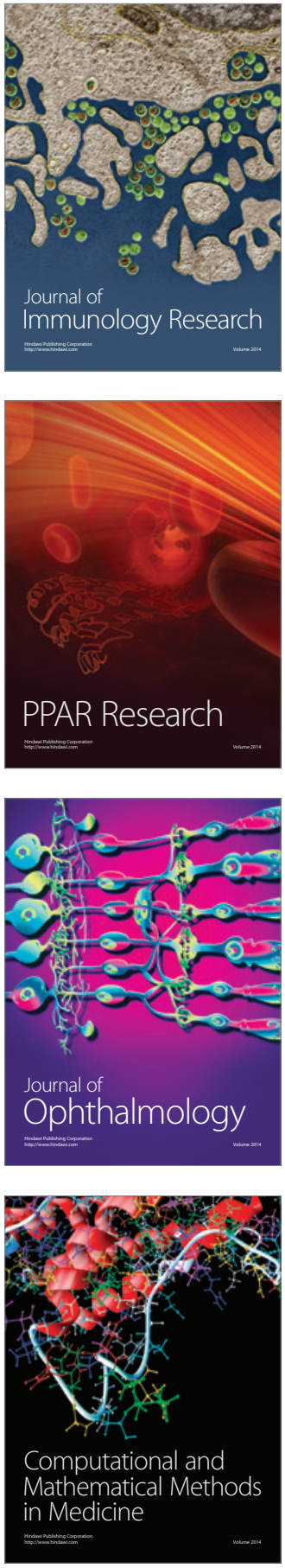

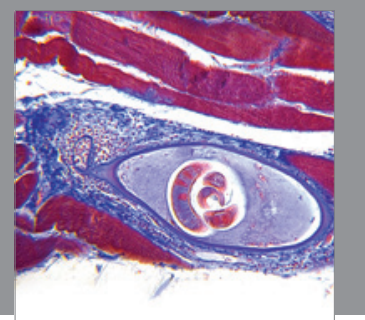

Gastroenterology

Research and Practice
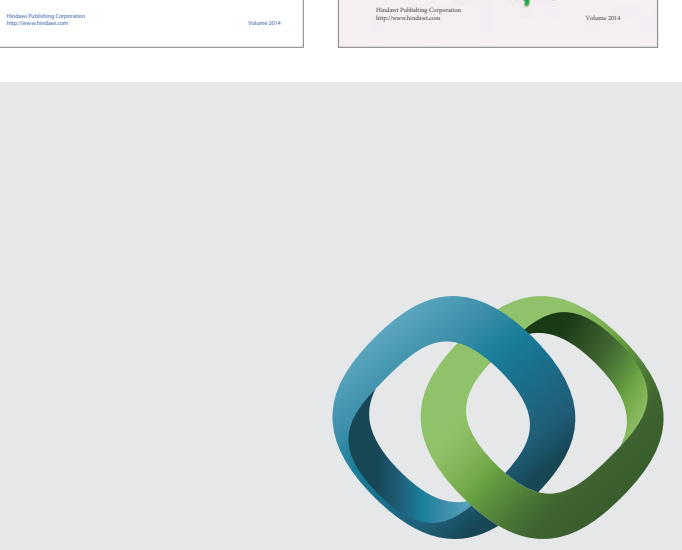

\section{Hindawi}

Submit your manuscripts at

http://www.hindawi.com
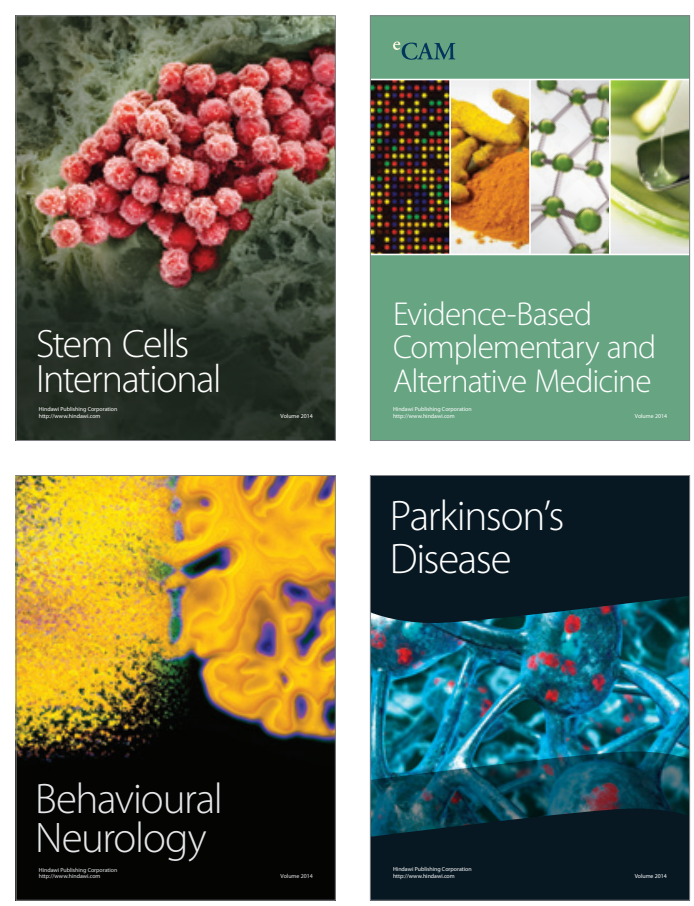

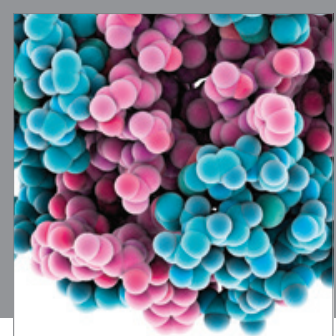

Journal of
Diabetes Research

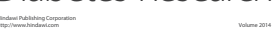

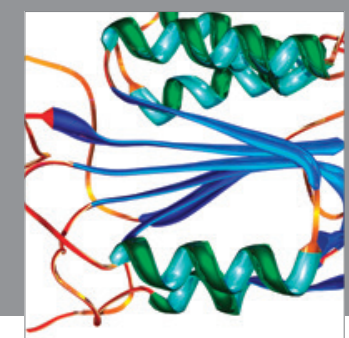

Disease Markers
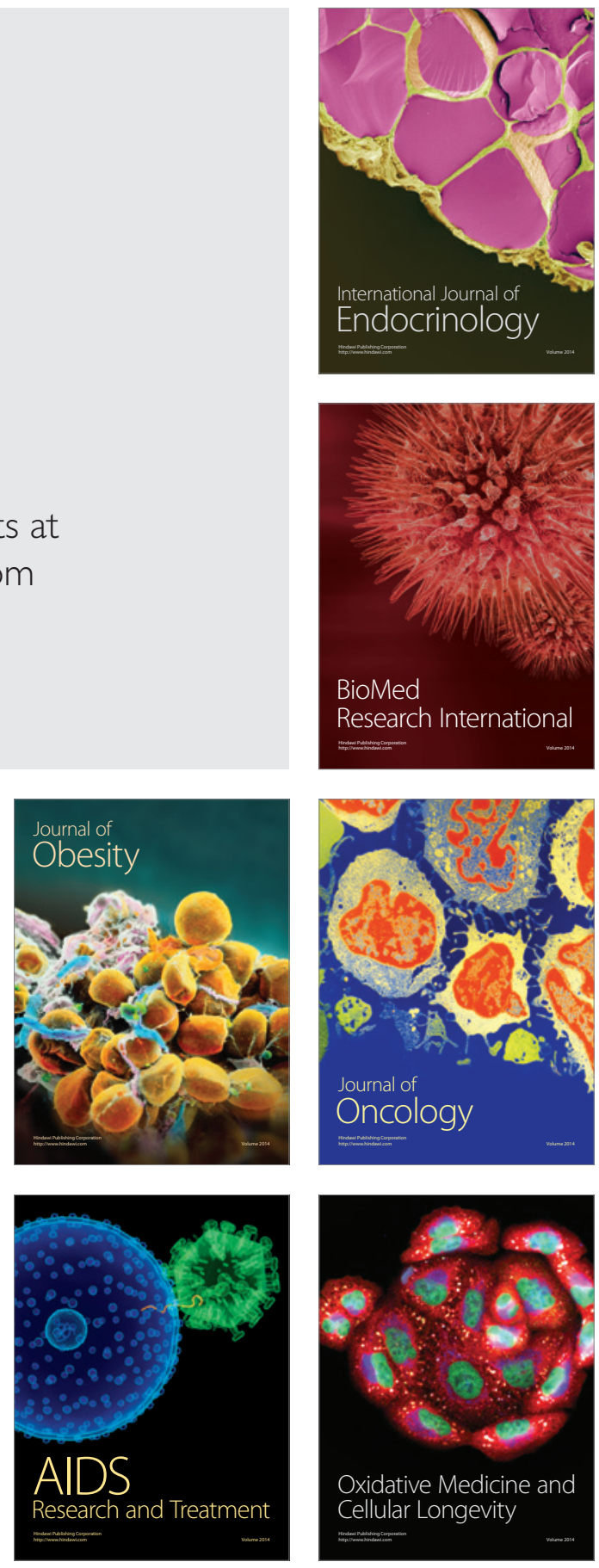